\title{
Dação em Pagamento do Único Bem Imóvel Familiar para a Quitação de Dívida Tributária Própria
}

\section{Donation in Payment of Only Family Property for the Settlement of Itself Tax Debt}

\author{
Bruna Alves de Jesus ${ }^{\mathrm{a}}$; Edvanda Soares da Silva ${ }^{\mathrm{a}}$; João Paulo Vasconcelos Caires ${ }^{\mathrm{ab}}$; Karina de Carvalho Santos ${ }^{\mathrm{a}}$; \\ Lorena Patrícia Basílio Morato*a; Mayara Alves Maia ${ }^{a}$ \\ ${ }^{a}$ Faculdade Pitágoras Betim, Curso de Direito. MG, Brasil. \\ bUniversidade Federal de Ouro Preto, Programa de Pós-Graduação Stricto Sensu em Sustentabilidade Socioeconômica e Ambiental. MG, Brasil \\ *E-mail: lorena_pbmorato@outlook.com
}

\begin{abstract}
Resumo
A dação em pagamento constitui uma das modalidades de exclusão do crédito tributário. Contudo, levando em consideração as várias formas de dar fim ao crédito tributário, dedicar-se a compreender melhor uma delas possibilita aos demais operadores do Direito maior domínio sobre as questões que envolvem a temática. Portanto, o objetivo do presente artigo é responder indagações como: existem limites para o poder de tributar? Qual o papel do Estado na regulamentação das ações de cunho tributário? Questionamentos dessa natureza, bem como outros que possam surgir, serão respondidos ao longo do trabalho, sem, contudo, findar as discussões envolvendo o assunto.
\end{abstract}

Palavras-chave: Tributo. Exclusão. Propriedade.

\begin{abstract}
The donation in payment is one of the many ways to exclusion from the tax credit. However, considering that there are other possibilities to end the tax credit it is so important dedicating ourselves to better understand one of them. This article may allows other Law defenders truly get the meaning of the issues surrounding the theme. Therefore, the purpose of this study is to answer questions such as: are there limits to the power to tax? What is the role of the State in the regulation of tax actions? Questions of this nature, as well as others that may arise, will be answered throughout the development, without, however, ending the discussions involving the subject.
\end{abstract}

Keywords: Tribute. Exclusion. Property.

\section{Introdução}

O Direito Tributário é uma ciência que se presta à arrecadação de dinheiro para o custeio e manutenção do Estado, não obstante, se encarrega também em limitar o poder estatal. Através destas ações a ciência tributária faz-se ferramenta essencial ao Estado Democrático de Direito e suas atribuições.

O Código Tributário Nacional de 1966 dispôs sobre vários institutos pertinentes à tributação, dentre eles emerge a dação em pagamento de bens imóveis como uma das modalidades de extinção do crédito tributário, circunstância esta que será analisada a luz do Direito Constitucional e do Direito de Família. Assim como os demais ramos do Direito, estudos envolvendo os tributos e suas implicações no ordenamento não podem ser realizados de modo isolado e superficial. Vale ressaltar que a base principiológica das ciências jurídicas são as mesmas, porém, nas circunstâncias de cada caso concreto surgem as especificidades de cada uma delas, o que demonstra objetivamente a importância de análises sistêmicas.

Face ao mencionado é possível observar que a construção deste artigo será realizada de maneira integrada, sobretudo no que tange à observância dos impactos e influências ocasionados frente à possibilidade da dação em pagamento do único bem familiar para a quitação de sua própria dívida tributária.

\section{Desenvolvimento}

\subsection{Metodologia}

O presente estudo, tomando por base produções doutrinárias, análise de legislação atualizada, bem como pesquisas, utilizando o método dedutivo, teve por objeto discorrer sobre a dação em pagamento nas hipótese de penhora do único imóvel de família. Para tanto, foi necessário debruçarmo-nos sobre diversos conceitos, princípios e atos normativos, com o intuito de reunir informações relevantes para a seara tributária.

\subsection{A evolução da ciência constitucional e sua relevância para os ramos do Direito}

A evolução da ciência jurídica é composta por uma série de fenômenos. No âmbito do Direito Constitucional vale ressaltar que tal área representa papel fundamental no ordenamento jurídico, posto que se trata de um ramo do direito público interno que tem o objetivo de organizar o Estado e estabelecer seus limites de atuação. (PINHO. 2010) O ordenamento jurídico brasileiro, desde que instituída a figura de um documento formal, escrito e dotado de complexidade, vislumbra uma gradativa evolução no modo de se pensar e 
disciplinar as relações sociais. De acordo com Lenza (2019, p.66), "no constitucionalismo moderno, predominam as constituições escritas como instrumento para conter qualquer arbítrio decorrente do poder".

A constitucionalização do Estado Moderno é um dos marcos da história do Direito. Tal fato possibilitou a primazia de uma base normativa única que teria como responsabilidade disciplinar a coletividade e estabelecer limites de atuação para os governantes. Tamanha é a importância de um documento que visa disciplinar as relações de poder que a hipótese de subjugar todos à lei foi tida como ideal máximo de igualdade.

A ideologia de limitação de poderes vai de encontro ao modelo de governo dos monarcas, tendo em vista que a vontade do rei era soberana e inquestionável. Buscando romper certos paradigmas, filósofos como Montesquieu e Rousseau desenvolveram teorias que influenciaram a organização da coletividade (PINHO. 2010, p.26); o primeiro sistematizou a Teoria da Separação dos Poderes, enquanto que ao segundo coube formular a Teoria do Contrato Social. No século XVIII a busca por estruturar um Estado que conseguisse equilibrar a proteção dos indivíduos, o respeito à propriedade privada e ainda evitar arbítrios trouxe parâmetros utilizados até os dias atuais. Para que houvesse segurança nas relações jurídicas, seja inter partes ou entre o indivíduo e o Estado, seria necessário disciplinar os limites de atuação de cada um dos agentes. É justamente neste contexto que ganha maior visibilidade o Direito Tributário.

A norma constitucional é responsável por estabelecer os princípios basilares de todos os demais ramos do ordenamento sob seu domínio. Na seara tributária tal realidade não se difere das demais, pois o Direito Constitucional Tributário, ou tão somente Direito Tributário:

é o conjunto de normas jurídicas que disciplina a atividade de tributação, levada a efeito pelo Estado e pelas entidades a ele relacionadas, de forma a que na cobrança de tributos e de penalidades pecuniárias decorrentes da infração a deveres tributários se observem critérios e limites pré-estabelecidos. (MACHADO SEGUNDO. 2018, p.40).

Logo, a criação do Direito Tributário é uma das formas mais claras de se estabelecer critérios de arrecadação, visto que é necessário o estabelecimento de uma série de regras para que o Estado possa angariar fundos e fazer valer seu poder de império, desde que o faça em consonância com os princípios estabelecidos na Constituição Federal.

\subsection{A importância do princípio da Legalidade para o Direito Tributário}

O princípio da legalidade, um dos mais importantes do ordenamento jurídico brasileiro, traz consigo uma característica fundamental do Estado Democrático de Direito, qual seja, a necessidade de se ter uma determinação escrita que visa garantir a primazia da legislação. $\mathrm{O}$ art. $5^{\circ}$, inciso II, da Constituição Federal diz "Ninguém será obrigado a fazer algo ou deixar de fazer senão em virtude da lei”. (BRASIL.
1988.)

A legalidade configura-se como um princípio que tem aplicabilidade em todos os ramos do Direito. Quando se faz menção ao princípio da legalidade no Direito Tributário, o objetivo máximo é assegurar aos contribuintes a existência de uma lei para criar e cobrar o tributo, bem como estabelecer limitações para o poder de império do Estado. Todos os atos praticados pelos entes tributantes têm a obrigatoriedade de seguir os parâmetros previamente estabelecidos pela legislação. A não observância de preceitos básicos acarretará em inconstitucionalidade do ato praticado, fazendo com que este perca sua finalidade.

Assim sendo, é possível concluir que o princípio da legalidade no Direito Tributário visa impedir eventuais arbítrios que possam ser cometidos pelas autoridades competentes. Carrazza (2019, p. 200) dita que a lei, quando estabelecer critérios de tributação, deve ser um conceito fechado e rígido, de maneira que atue para reforçar a segurança jurídica.

\subsection{Classificação dos tributos no Brasil}

Tributo, segundo o art. $3^{\circ}$ do Código Tributário Nacional, "É toda prestação pecuniária compulsória, em moeda ou cujo valor nela se possa exprimir, que não constitua sanção de ato ilícito, instituída em lei e cobrada mediante atividade administrativa plenamente vinculada". Para entender melhor o que o legislador quis dizer ao descrever o conceito de tributo deve-se fragmentar o dispositivo. Para melhor interpretação: tributo é prestação, que na natureza jurídica dentro do direito tributário é uma obrigação de dar (dinheiro), de forma compulsória (sem escolha/obrigatório), que não constitui ato ilícito, ou seja, tributo não é multa, mas sim uma obrigação a ser paga por todos, além de serem, sem exceção, instituídos por lei.

O Sistema Tributário Nacional comporta as modalidades descritas no art. $5^{\circ}$ do CTN. Uma delas é o imposto, que é um tributo não vinculado, portanto, seu fato gerador depende do ato ocorrido ao particular. Um exemplo de imposto é o IPTU - Imposto Predial e Territorial Urbano - pago anualmente por proprietários de imóveis urbanos. Por seu turno, as taxas possuem como fato gerador uma atividade estatal, ou seja, o Estado presta algum serviço ou então o deixa à disposição da sociedade. As contribuições de melhoria são outra espécie de tributo e se caracterizam pelo fato de que seu pagamento decorre de obras públicas que tenham por consequência a valorização de determinado local, como pode ser o caso de uma estrada pavimentada que aumentará o fluxo de pessoas e por conseguinte aumentará a arrecadação, caso exista algum comércio ou qualquer fonte de renda.

Existem ainda os empréstimos compulsórios, que são outra modalidade de tributo e podem ser instituído somente pela União em casos previamente determinados pela lei. Sua materialização na órbita tributária depende da comprovação de calamidade pública, guerra externa declarada, ou sua 
iminência. Por fim, as contribuições especiais estão previstas constitucionalmente e são finalísticas, qualificadas pelos seus resultados. Ou seja, não estabelece um conceito da modalidade de tributo, trata-se apenas de sua previsão constitucional.

\subsection{Direito à propriedade, função social da propriedade e conflitos de interesses}

Pinho (2010, p.96) conceitua direitos fundamentais da seguinte maneira: "são aqueles indispensáveis à pessoa humana, necessários para assegurar a todos uma existência digna, livre e igual". A Constituição da República Federativa do Brasil de 1988, denominada também de Constituição Cidadã, recebeu tal alcunha em razão do período em que foi promulgada. No final da década de 80 o país passara por enormes transformações em decorrência do término da ditadura militar, que perdurou por aproximadamente 20 anos no país. O art. $5^{\circ}$ da CRFB de 1988 é um dos principais a estabelecer direitos e garantias fundamentais. Neste contexto, merecem destaque os incisos XXII e XXIII, que abordam respectivamente a previsão da garantia do direito de propriedade e também trata sobre a necessidade de a propriedade atender à função social.

A possibilidade de manter uma propriedade figura como um direito de primeira dimensão, isto porque seu desenvolvimento se deu num contexto histórico no qual a sociedade desejava maior autonomia face ao Estado. Buscava-se também o direito de reunir riquezas sem que a Coroa - representada sobretudo pela figura de um rei - viesse a confiscar ou exigir tributos de forma desmedida. Os direitos humanos de primeira geração marcam a passagem de um Estado autoritário para um Estado de Direito e, nesse contexto, o respeito às liberdades individuais, em uma verdadeira perspectiva de absenteísmo estatal. (LENZA, 2019, p.1156)

No âmbito do Direito Constitucional, Pinho (2010) conceitua a propriedade de forma ampla, explicitando que sua abrangência vislumbra qualquer direito de cunho patrimonial ou econômico, de caráter pessoal, que possa ser convertido em dinheiro. Para além do direito de propriedade, o inciso XXIII do art. $5^{\circ}$ determina que a propriedade atenderá à função social. Isso significa dizer que o gozo do bem em análise deverá ser realizado dentro dos parâmetros sociais para a utilização da coisa de modo a preservar não só os anseios daquele que é dono de determinada coisa, como também aos demais integrantes da sociedade.

Importante salientar que a Administração Pública se encarrega em gerir o Estado em observância aos limites legais, com isso deve realizar ponderações no que diz respeito à aplicação do Princípio da Supremacia do Interesse Público, pois não pode se abster de tributar e arrecadar, contudo, suas ações também não devem figurar de maneira a retirar ou diminuir a dignidade humana. Privar o direito à moradia afronta o princípio da dignidade da pessoa humana, inflama os princípios morais e sociológicos. É notório que o bem de família é um processo existente no ordenamento jurídico, e isso reafirma a sua importância, pois traz para a instituição familiar a garantia e sentimento de segurança do lar onde residem.

\subsection{Imposto sobre a Propriedade Predial e Territorial Urbana (IPTU): conceito e hipótese de incidência}

O art. 156 da CRFB de 1988 determina que é de competência do município instituir o Imposto sobre a Propriedade Predial e Territorial Urbana (IPTU). Esta previsão no texto constitucional é a responsável por identificar o sujeito ativo da relação tributária, qual seja o ente federado de nível local. O Código Tributário Nacional (CTN), reforçando a vontade do constituinte originário, dispõe novamente em seu art. 32 à quem cabe a responsabilidade de arrecadar o IPTU. Ainda no que tange ao CTN, cabe ao art. 34 estabelecer quem é o sujeito passivo, ou seja, quem é o agente responsável por arcar com a responsabilidade tributária nos casos em que incide o IPTU. Neste cenário, o artigo em tela define o seguinte: "Contribuinte do imposto é o proprietário do imóvel, o titular do seu domínio útil, ou o seu possuidor a qualquer título." (BRASIL, 1966).

Há a possibilidade de que a lei municipal responsável por instituir o IPTU estabeleça regras de isenção, normalmente para os aposentados e proprietários que possuem baixa renda ou cujos imóveis não são de valor significativo. Porém, para aqueles que não são resguardados pelas regras de isenção, o não-pagamento do IPTU resultará na inscrição do nome do inadimplente na dívida ativa do município. A partir de tal situação, iniciará então um prazo de cinco anos para que a dívida seja sanada, ou pela negociação entre o inadimplente e o Estado, ou por ação de execução fiscal através do Poder Judiciário. Passados os cinco anos, ocorre a prescrição da dívida e o cidadão não precisa mais pagar. Em caso de execução fiscal, o devedor poderá ter seus bens confiscados para que haja o abatimento da dívida. Se o devedor não houver bens para serem confiscados, o próprio imóvel poderá ser penhorado, mesmo que este configure bem de família.

\subsection{Hipóteses de incidência e fato gerador do IPTU}

As hipóteses de incidência tributária são definidas por previsão legal e abstrata, ou seja, uma descrição hipotética de uma situação que, quando concretizada com o fato gerador, enseja a tributação. A modalidade tributária em voga tem como fato gerador a propriedade, o domínio útil ou a posse de bem imóvel por natureza ou por acessão física, como definido na lei civil, localizado na zona urbana do município (BRASIL, 1988.). Nesse contexto, vale a pena ressaltar o que a lei civil conceitua como "domínio útil ou a posse". De acordo com o Código Civil de 2002, considera-se possuidor todo aquele que tem de fato o exercício, pleno ou não, de algum dos poderes inerentes à propriedade (BRASIL, 2002).

A norma tributária preocupa-se em estabelecer as características necessárias para que determinado local seja considerado pertencente à zona urbana. Em seu $\S 1^{\circ} \mathrm{o}$ art. 32 do CTN traz as seguintes determinações: possuir meio- 
fio ou calçamento que conta com canalização de águas pluviais, deve haver ainda abastecimento de água, sistema de esgotos sanitários e rede de iluminação pública, com ou sem posteamento para distribuição domiciliar. Ainda faz parte dos requisitos a existência de escola primária ou posto de saúde a uma distância máxima de três quilômetros do imóvel considerado. Porém, de acordo com a súmula 626 do STJ, a incidência do IPTU não está condicionada a existência dos melhoramentos elencados no art.32, $\S 1^{\circ}$ do CTN.

Já se tratando do cálculo, conforme a legislação tributária da maioria dos municípios do país é adotada as hipóteses de incidência do IPTU tendo em vista o valor venal do imóvel, sendo que este valor venal será calculado levando em consideração as plantas genéricas de valores imobiliários de cada município e suas alíquotas, plantas estas definidas também por estas legislações tributárias acima mencionadas. Há uma clara diferença em relação às cobranças realizadas em residências, lotes vagos, comércios e demais. Esta diferença se caracteriza pela adoção da respectiva alíquota para cada um destes itens citados.

Na grande maioria dos municípios, as residências têm sua alíquota menor que os demais tipos de imóveis. Um exemplo disto é a legislação do IPTU de Belo Horizonte, onde a alíquota para as residências que tem o valor venal do imóvel entre $\mathrm{R} \$ 800.000,00$ e R \$ $1.000 .000,00$ é de $0,9 \%$, enquanto que para os lotes ou terrenos não edificados com valor venal entre R\$600.00,00 e R\$ 1.000.000,00 a alíquota é de 2,5\%.

\subsubsection{A dação em pagamento como modalidade de extinção da dívida do IPTU}

A princípio é importante ponderar que a obrigação tributária nasce com o acontecimento do fato gerador. No entanto, o crédito tributário somente surge inevitavelmente após o lançamento, que conforme preceitua Carneiro (2020, p.633): "O lançamento é uma série de atos vinculados praticados pela Administração Fazendária com o objetivo de qualificar a obrigação tributária ilíquida, transformando-a em um crédito líquido e certo, apto para pagamento.” O artigo 156 do CTN definiu as hipóteses de extinção do crédito tributário, quais sejam:

I - o pagamento; II - a compensação; III - a transação; IV remissão; V - a prescrição e a decadência; VI - a conversão de depósito em renda; VII - o pagamento antecipado e a homologação do lançamento nos termos do disposto no artigo 150 e seus $\S \S 1^{\circ}$ e $4^{\circ}$; VIII - a consignação em pagamento, nos termos do disposto no $\S 2^{\circ}$ do artigo 164; IX - a decisão administrativa irreformável, assim entendida a definitiva na órbita administrativa, que não mais possa ser objeto de ação anulatória; X - a decisão judicial passada em julgado; XI - a dação em pagamento em bens imóveis, na forma e condições estabelecidas em lei

A dação em pagamento é um acordo entre credor e devedor. Diante disso, os efeitos da extinção total ou parcial do crédito sobre a posterior verificação da irregularidade da sua constituição é uma das modalidades, qual seja indireta de extinção de crédito tributário, vez que é necessária, para a sua aplicação, edição de lei específica que estabeleça a forma e condições exigidas para que os créditos tributários sejam extintos pela dação em pagamento de bens imóveis, conforme o artigo $3^{\circ}$ do $\mathrm{CTN}$, onde conceitua o tributo como prestação pecuniária ou em cujo valor nela se possa exprimir.

De acordo com os artigos 356 a 359 do Código Civil, a dação trata-se de um instituto jurídico onde o credor e o devedor fazem um acordo. Na situação em pagamento, é fundamental o consentimento do credor, tornando assim um negócio jurídico bilateral.

A apuração do pagamento é um acordo feito entre o devedor e a Fazenda, no qual os bens imóveis sejam avaliados, e o valor apurado seja abatido, assim fazendo com que o devedor perca o seu bem imóvel como forma de pagamento. Vale ressaltar que os bens móveis serão utilizados para quitação de débito tributário somente na apresentação de uma lei ou mandamento no sentido de permitir. Caso não apresente uma das opções acima, essa modalidade não pode ser aplicada.

Um pouco mais sobre as formas excepcionais da Dação; A dívida sendo em dinheiro, não se consiste em uma datio in solutum, quando se é feito um depósito numerário em conta bancária, já acordada com o credor, em forma de pagamento normal. O resultado é o mesmo quando o devedor emite uma ordem de pagamento, ou passa um cheque ao credor. Dessa forma, a entrega do cheque depósito feito ao credor ou ordem de pagamento podem sim configurar dação em pagamento, sendo a prestação devida diversa (entregar um animal, ou um veículo, ex.) obviamente se o credor concorda com as formas de cumprimento, em substituição a convencionada.

\subsection{Aspectos do Direito de Família}

O bem de família é um instituto do Direito Civil que pode conter diversos desdobramento no âmbito jurídico, neste momento buscamos estabelecer um contexto histórico acerca da necessidade de ser ter uma propriedade familiar. Polido e Amaral (2005) conceituam o bem de família como sendo um asilo, local onde se instala o domicílio da família, situação que traz à tona a sua impenhorabilidade. Sendo assim, fica clara a ideia de que se busca garantir a segurança da família, de modo que seus integrantes possam contar com um espaço destinado ao exercício de sua dignidade, bem como concentrar seu patrimônio em local próprio.

No Brasil, o ramo do Direito que regula as relações familiares sofreu significativas modificações ao longo dos anos, pois com o desenvolver da sociedade foi preciso ressignificar o termo família. A adoção ganhou mais espaço e as famílias monoparentais passaram a ser uma realidade comum; desta e de tantas outras formas houve maior diversidade e gradualmente ocorreu a despersonalização de um modelo considerado antes como padrão para uma relação em que o afeto, o cuidado e a felicidade são características primordiais para que os mais variados grupos sejam considerados entidades familiares. 
A manutenção da família implica que esta desfrute de um local digno para exercer o direito social à moradia, constitucionalizado no artigo $6^{\circ}$ da CRFB de 1988. O dispositivo ora citado vincula ainda o princípio da dignidade da pessoa humana com o exercício do mínimo existencial. Conforme Faria e Rosenvald (2019, p 862):

Enfim, relaciona a garantia de um mínimo patrimonial à dignidade da pessoa humana, percebe-se o objetivo almejado pela Constituição da República no sentido de garantir a erradicação da pobreza e a redução das desigualdades sociais, funcionalizando o patrimônio como um verdadeiro instrumento de cidadania e justificando a separação de uma parcela essencial, básica, do patrimônio para atender às necessidades elementares da pessoa humana.

Nesse sentido, o Código Civil de 2002 dedicou do artigo 1.711 ao 1722 para dispor sobre o bem de família, instituto este que se configura por ser um imóvel, submetido à escritura pública, destinado ao convívio diário familiar. A segurança jurídica da manutenção desse bem em posse da família se dá através da Lei no 8.009 de 29 de março de 1990, que versa sobre sua impenhorabilidade.

\subsubsection{Considerações acerca do único imóvel que compõe o bem de família}

Historicamente, o Direito Civil visa proteger o patrimônio; a partir da promulgação da Constituição Federal de 1988 foram feitas ressignificações na seara cível, tendo em vista que a dignidade da pessoa humana passou a ser um dos fundamentos da nova ordem jurídica. No que diz respeito ao bem de família, é válido lembrar que seu resguardo é feito através de duas leis, a primeira é a lei 8009/90 e a segunda é a lei 13.144/15.

O bem de família abarca algumas classificações, podendo ser convencional, que é aquele que decorre da vontade dos interessados, estando disposto no código civil nos art 1711 ao 1722, nesta modalidade, implica na impenhorabilidade e inalienabilidade do bem, ou seja, se a pessoa quiser convencionar esta coisa, a legislação não permite que o mesmo seja objeto de penhora e nem objeto de alienações. Já o bem de família legal é caracterizado por não depender de manifestação da vontade do iniciador, disposto na lei 8009/1990, por isso implica tão somente na impenhorabilidade da moradia da pessoa e de sua família, essa lei tem por objetivo garantir a dignidade da pessoa humana, bem como o mínimo patrimonial para a pessoa e sua família não fiquem desamparadas. Nesta hipótese o bem de família não pode ser atingido por processo de execução trabalhista, civil, previdenciário e de outra natureza.

Vale a pena ressaltar que existem algumas exceções a regra de impenhorabilidade do bem de família, conforme dispõe o art $3^{\circ}$ da lei 8009/90. Diferente da penhora, que é um ato involuntário ocasionado pela execução processual, a dação de bem imóvel familiar é ato volitivo, ou seja, depende exclusivamente da vontade do devedor. Visto que dação em pagamento é uma maneira de se dispor de determinado bem, as possibilidades da realização desta ação no que tange ao único imóvel familiar pode ser analisada de maneira análoga ao instituto da penhora, sendo observado seus impactos. É notório que o bem de família é um processo existente no nosso ordenamento jurídico, e há de ser reafirmada a sua importância, pois traz a instituição familiar a garantia e sentimento de segurança do lar onde residem.

\subsection{A ameaça ao direito à moradia e suas implicações no que concerne aos Direitos Humanos}

O objetivo é que o indivíduo garanta seu bem-estar, preservando sua dignidade, assim protegendo a si mesmo e a sua família. Ao analisar sobre os aspectos jurídicos referentes ao único imóvel da família e do direito à moradia, não há como deixar de ressaltar o contexto histórico em que eles se encaixam. O direito à habitação é um direito fundamental e social que constitui o dever do Estado de garantir o mínimo existencial, que está diretamente relacionado com a dignidade da pessoa humana. A Declaração Universal dos Direitos Humanos de 1948 (DUDH) deu início para que os demais tratados, ordenamentos jurídicos e até a Constituição de 1988 adotassem através da Emenda 26/2000 a ideia de que todos tenham como garantia uma habitação digna. No que concerne ao único imóvel da família, não há previsão na $\mathrm{CF} / 88$ que trata expressamente sobre o tema, porém, isso não significa dizer que não existam outras disposições legais que resguardam esse direito.

\section{Conclusão}

Por meio dos estudos aqui presentes tentamos ampliar um pouco as questões envolvendo a dação em pagamento como uma das modalidades de se extinguir o crédito tributário. Ao final da pesquisa foi possível observar que não se trata de um assunto difundido, posto que a ciência jurídica, seguindo seu caráter mutável, sempre trará novas perspectivas aos ávidos pelo conhecimento.

O Princípio da Legalidade mostrou-se como um dos mais importantes de todo o ordenamento jurídico, uma vez que seu caráter limitador do poder estatal se materializa no mundo fático-jurídico, o que consequentemente acarreta num instrumento que garante a possibilidade de se cobrar dos indivíduos tão somente o que se encontra positivado na norma, de maneira a evitar arbítrios.

Interessante relembrar também o quanto áreas tidas como "distantes" dentro do arcabouço legal podem se relevar mais próximas do que jamais se imaginou. De um lado é possível observar como o Direito de Família, disciplina que compõe o Direito Privado, tem sido ressignificada ao passar dos anos, muito em razão do desenvolvimento social e da mudança de paradigmas. Na outra ponta está a ciência tributária, ramo do Direito Público que, além de limitadora do poder de império exercido pelo Estado, possui enorme função social 
na arrecadação e distribuição dos tributos. Ambas as normas, ainda que numa análise superficial não estejam diretamente relacionadas, decorrem da mesma fonte normativa e obedecem a princípios em comum, motivo pelo qual se vislumbra a busca por assegurar a dignidade da pessoa humana em qualquer uma das matérias.

Ao longo do trabalho, o que se buscou foi apresentar a dação em pagamento e alguns de seus desdobramentos. No ordenamento jurídico atual é inegável a relevância que alguns institutos possuem, e por tal razão o presente texto não visa em momento algum dar cabo a temática ora exposta. O que se objetivou foi dar início a uma nova problemática que muito em breve poderá figurar como demanda judicial.

Tanto pesquisas doutrinárias quanto jurisprudenciais demonstram que o temática ainda não está pacificada entre os operadores do Direito. Considerando a complexidade da demanda é perfeitamente possível que muito se discuta até que haja consenso sobre a possibilidade de dação e pagamento de único imóvel para a quitação do Imposto Predial e Territorial Urbano (IPTU). Ainda que não seja possível encontrar resposta definitiva para o problema exposto, tem-se por meio do presente artigo um novo questionamento pairando sobre a cabeça dos interessados pela ciência do Direito, portanto, mesmo sem responder diretamente à problemática sugerida, aqui se inicia uma nova linha de pensamento.

\section{Referências}

BRASIL. Constituição da República Federativa do Brasil de 1988. Disponível em <http://www.planalto.gov.br/ccivil_03/ constituicao/constituicaocompilado.htm $>$. Acesso em: 5 maio 2020.

BRASIL. Lei $\mathrm{n}^{\circ} 8.009$, de 29 de março de 1990. Dispõe sobre a impenhorabilidade do bem de família. Disponível em: $<\mathrm{http}: / /$ www.planalto.gov.br/ccivil_03/leis/L8009.htm>. Acesso em: 15 maio 2020.

BRASIL, Lei $\mathrm{n}^{\circ} 5.172$ de 25 de outubro de 1966. Dispõe sobre o Sistema Tributário Nacional e institui normas gerais de direito tributário aplicáveis à União, Estados e Municípios. Disponível em <http://www.planalto.gov.br/ccivil_03/leis/15172.htm>.
Acesso em: 5 maio 2020.

BRASIL, Lei $n^{\circ} 10.406$, de 10 de janeiro de 2002. Institui o Código Civil. Disponível em <http://www.planalto.gov.br/ ccivil_03/leis/2002/110406.htm\#posse título i>. Acesso em: 5 maio 2020 .

CARlOMAGNO, F. Ponderações do Direito Tributário. DireitoNet, 2005. Disponível em: <https://www.direitonet.com. br/artigos/exibir/2037/Ponderacoes-ao-Direito-Tributario.> Acesso em: 26 abr.2020.

CARNEIRO, C. Curso de Direito Tributário e Financeiro. São Paulo: Saraiva, 2020.

CARRAZZA, R.A. Curso de Direito Constitucional Tributário. São Paulo: Saraiva, 2019.

FÉLIX, G.V. Direito Tributário: Direito Constitucional Tributário. Londrina: Editora e Distribuidora Educacional, 2018.

FARIA, C.C.; ROSENVALD, N. Curso de Direito Civil. Famílias. Salvador: Jus Podium, 2019.

IPTU. Belo Horizonte, 2009. Disponível em: <www.fazenda.pbh. gov.br/internet/legislação/formkey.asp?key=532>. Acessado em: 07 de Maio de 2020.

LENZA, P. Direito Constitucional esquematizado. São Paulo: Saraiva, 2019.

PINHO, R.C.R. Teoria geral da constituição e direitos fundamentais. São Paulo: Saraiva, 2010.

POLIDO, P.S.; AMARAL, S.T. Origem do bem de família. In: ETIC-ENCONTRO DE INICIAÇÃO CIENTÍFICA, v. 1, n. 1, 2005.

PREPARATÓRIO, Pródige. Finalidade Dos Tributos - Direito Tributário. 2018. Disponível em: < https://www.youtube.com/ watch? $\mathrm{v}=\mathrm{A} 5 \mathrm{dBvgVyEq} 8>$

RIBEIRO, P.S. O papel do Estado segundo Thomas Hobbes. Disponível em: <https://brasilescola.uol.com.br/sociologia/opapel-estado-segundo-thomas-hobbes.htm>. Acesso em: $21 \mathrm{abr}$. 2020.

SUPERIOR TRIBUNAL DE JUSTIÇA. Súmula 626, publicada em 12.12.2018 e disponibilizada no DJe em 17.12.2018. Disponível em: <www.scon.stj.jus.br/SCON/sumanot/ tocjsp?materia $=\% 27$ DIREITO $\% 20$ TRIBUT $\%$ C 1 RIO $\% 27$. mat $>$ Acesso em: 15 abr. 2020. 